\title{
Direito ao Meio Ambiente de Trabalho Saudável: A Construção de Respostas Jurídicas Apropriadas aos Novos Direitos e Deveres Decorrentes das Nanotecnologias ${ }^{1}$
}

\author{
Maria Cândida Simon Azevedo Nascimento \\ Especialista em Direito e Processo do Trabalho pela Uni- \\ versidade do Vale do Rio dos Sinos (2015). Graduada \\ em Direito pela Universidade do Vale do Rio dos Sinos \\ (2012). Advogada. kandida8@hotmail.com
}

\section{Wilson Engelmann}

Doutor e mestre em Direito Público pelo Programa de Pós-Graduação em Direito (Mestrado e Doutorado) da Universidade do Vale do Rio dos Sinos - Unisinos/RS/ Brasil; professor deste mesmo Programa das atividades: "Transformações Jurídicas das Relações Privadas" (Mestrado) e "Os Desafios das Transformações Contemporâneas do Direito Privado" (Doutorado); coordenador exe-

1 Este artigo é o resultado parcial do seguinte projeto de pesquisa desenvolvido pelos autores: "Desenhando modelos regulatórios para nanomateriais no Brasil a partir da adaptação de estruturas normativas internacionais: especificando o cenário para o diálogo entre as fontes do Direito e a juridicização dos fatos nanotecnológicos”: Bolsa de Produtividade em Pesquisa do CNPq; b) "Observatório dos Impactos Jurídicos das Nanotecnologias: em busca de elementos essenciais para o desenvolvimento do diálogo entre as Fontes do Direito a partir de indicadores de regulação às pesquisas e produção industrial com base na nano escala”: Edital Universal 14/2014 - CNPq; c) “As transformações jurídicas das relações privadas: a construção de marcos regulatórios e a revisão de categorias tradicionais do Direito como condição de possibilidade para atender aos desafios das mutações jurídicas contemporâneas geradas pelas novas tecnologias” (Unisinos). 
cutivo do Mestrado Profissional em Direito da Empresa e dos Negócios da Unisinos; líder do Grupo de Pesquisa Jusnano (CNPq); bolsista de Produtividade em Pesquisa do CNPq. wengelmann@unisinos.br

\title{
Resumo:
}

0 direito ao meio ambiente do trabalho saudável é direito fundamental de todo trabalhador. 0 passar dos anos e a evolução tecnológica não atenuou os riscos decorrentes do trabalho insalubre. As nanotecnologias, constituindo o maior e mais recente avanço da ciência, possibilitam a criação e a modificação da matéria em escala nanoscópica, equivalente à bilionésima parte do metro. Sua aplicação tem infinitas utilidades em diversos ramos da indústria. Por se tratar de uma inovação, possíveis riscos imediatos ou futuros ao meio ambiente, em especial do trabalho, parecem ser inevitáveis. Há necessidade de regulamentação/regulação acerca da matéria. 0 Direito, entretanto, ainda não se estruturou adequadamente a fim de responder aos desafios propostos por essa inovação tecnológica. Assim sendo, deve encontrar um meio de regular a (im)previsibilidade de possíveis riscos decorrentes das nanotecnologias, utilizando-se para tanto, da ferramenta da árvore de decisão e do princípio da precaução.

Palavras-chave: Meio ambiente. Trabalho. Nanotecnologias. Árvore de decisão. Princípio da precaução.

\section{Right To A Healthy Working Environment: The construction of appropriate legal responses to the new rights and obligations arising from nanotechnologies}

\begin{abstract}
:
The right to an environment of healthy work is a fundamental right of every worker. The passing of time and technological developments didn't attenuate the risks of unhealthy work. Nanotechnologies are the latest and greatest advancement of science, enables the creation and modification of matter at nanoscale, equivalent to one billionth of a meter. Its application has endless uses in various branches of industry. Because it is an innovation, possible immediate or future risk to the environment, especially the work appear to be inevitable. There regulatory requirement on the matter. However, the law has not been properly structured to respond to the challenges posed by this technological innovation. Therefore, you must find a way to regulate the (un) predictability of possible risks of nanotechnology, using for that purpose, the decision tree tool and the precautionary principle.
\end{abstract}

Keywords: Environment. Work. Nanotechnologies. Decision tree. Precautionary principle.

\section{Sumário:}

1 Introdução. $2 \mathrm{O}$ Meio Ambiente do Trabalho. 2.1 Conceito de meio ambiente do trabalho (saudável). 3 O Direito ao Meio Ambiente do Trabalho Saudável e as (In)Certezas das Nanotecnologias. 3.1 O que são nanotecnologias? 3.2 Os riscos ao trabalhador decorrentes das nanotecnologias. 4 Princípio da Precaução e Árvore de Decisão: em busca de respostas jurídicas apropriadas aos novos direitos e deveres decorrentes das Nanotecnologias. $4.1 \mathrm{O}$ princípio da precaução. 4.2 A árvore de decisão como ferramenta para a aplicação do princípio da precaução na busca de respostas jurídicas apropriadas aos novos direitos e deveres decorrentes das nanotecnologias. 5 Conclusão. 6 Referências. 


\section{INTRODUÇÃO}

O presente trabalho visa a estudar o meio ambiente de trabalho com enfoque na aplicação da árvore de decisão e do princípio da precaução em razão das (in)certezas decorrentes das nanotecnologias. Como o futuro com nanotecnologias constitui uma incógnita até mesmo para a ciência, esta não pode ser utilizada indistintamente no âmbito do local de trabalho sem parâmetros mínimos de precaução à saúde dos trabalhadores. Trata-se de questão de grande relevância, pois, em que pesem as nanotecnologias não serem de conhecimento geral, já fazem parte de muitos produtos ofertados no mercado. Assim, o enfoque do presente estudo está nos riscos aos trabalhadores decorrentes dessa nova tecnologia, a nanotecnologia. Apesar do avanço da ciência, as mortes por acidentes de trabalho e, em especial, doenças ocupacionais, não estão diminuindo. Com o ingresso descontrolado dessas novas tecnologias no ambiente do trabalho a saúde e a vida do trabalhador podem ser ainda mais prejudicadas. Assim, a problemática alvitrada é analisar o que o Direito pode propor para que essa nova tecnologia, tão promissora, não coloque em risco a vida de muitos trabalhadores.

Primeiramente, no item dois, será feita uma análise acerca do que é meio ambiente do trabalho e suas principais características, demonstrando-se como as doenças profissionais não estão em processo de extinção, mas sim ocorrem com muito mais frequência do que gostaríamos. Ademais, será abordada a importância do meio ambiente do trabalho saudável, bem como os riscos decorrentes do meio ambiente de atividade insalubre e a consequente condenação do empregador pelo descumprimento de normas atinentes à saúde, higiene e segurança do trabalho.

No tópico três propõe-se, então, conceituar o que são as nanotecnologias e as incertezas decorrentes dessa nova tecnologia. Demonstram-se as inseguranças que nem mesmo a ciência pode resolver até o presente momento, posto que não sabemos como partículas manipuladas pelo 
homem em escala nano podem se comportar em contato com o meio ambiente e, em especial, com o ser humano. Assim, coloca-se em pauta o risco dos trabalhadores que laboram com esse novo tipo de tecnologia, pois o que se observa é uma tranquilidade da área jurídica no tocante a utilização das nanotecnologias no ambiente de trabalho.

Finalmente, no quarto item será aprofundado o estudo acerca da utilização da ferramenta da árvore de decisão e do princípio da precaução como forma de promover a proteção ao meio ambiente do trabalho saudável em razão das (in)certezas decorrentes do uso das nanotecnologias no mundo laboral. Mostra-se, inclusive, recente utilização do princípio da precaução em julgado de dissídio coletivo do Tribunal Regional do Trabalho da Décima Quinta Região (Campinas/SP), no qual há aplicação do princípio em questão.

Dessa forma, o presente estudo justifica-se tendo em vista a urgência na necessidade de realização de estudos mais aprofundados acerca dos riscos decorrentes das nanotecnologias, pois o que não pode ocorrer é trabalhadores ficarem à mercê de empresas que queiram utilizar-se dessa nova tecnologia sem qualquer cautela prévia, colocando, assim, em risco o meio ambiente do trabalho saudável.

\section{O MEIO AMBIENTE DO TRABALHO}

O meio ambiente do trabalho passou a ser analisado com extrema cautela nas últimas décadas. $\mathrm{O}$ crescimento descontrolado da indústria e a ocorrência de diversos tipos de acidentes e doenças envolvendo o trabalhador influenciaram no surgimento de leis e outros tipos de mecanismos de proteção. Um fator importante na tutela do ambiente de trabalho foi a Revolução Industrial do século 18, que, em razão do desenvolvimento exacerbado da produção em massa, ocasionou a necessidade de regulamentação legal acerca da matéria. No plano internacional, a Organização 
Internacional do Trabalho (OIT) também desempenhou papel fundamental no desenvolvimento do assunto por meio da Convenção 155, lançada em 22 de junho de 1981, a qual discorre acerca da segurança e saúde dos trabalhadores (ORGANIZAÇÃO..., 1981). Seguindo a mesma linha, a Constituição Federal de 1988, corroborando com o que vinha sendo desenvolvido pelo Direito para proteção dos trabalhadores, inovou no ordenamento jurídico brasileiro dando ênfase à matéria (SANCHEZ, 2009).

Assim, importante se faz realizar uma análise, ainda que sucinta, acerca do conceito de meio ambiente do trabalho, consoante se fará a seguir, para após analisar o que é nanotecnologia e sua implicação no âmbito do Direito do Trabalho, mais especificamente no meio ambiente do trabalho.

\subsection{Conceito de meio ambiente do trabalho (saudável)}

O meio ambiente do trabalho saudável está previsto tanto no artigo $7^{\circ}$, inciso XXII, ${ }^{2}$ quanto no artigo 200, inciso VIII, ${ }^{3}$ ambos da Constituição Federal. O meio ambiente do trabalho integra, portanto, o meio ambiente lato sensu, fazendo parte dos direitos fundamentais, tanto de segunda geração (segurança e medicina do trabalho), quanto de terceira geração (meio ambiente), principalmente por dizer respeito à dignidade da pessoa humana, que, inclusive, é fundamento da República Federativa do Brasil (GARCIA, 2012). Nesse sentido, o direito ao meio ambiente saudável é direito fundamental de todo trabalhador, e sua afronta vitima não apenas o trabalhador, mas toda a sociedade, inclusive também em razão de ser esta quem custeia a Previdência Social.

2 “Art. 7º . São direitos dos trabalhadores urbanos e rurais, além de outros que visem à melhoria de sua condição social: [...] XXII - redução dos riscos inerentes ao trabalho, por meio de normas de saúde, higiene e segurança” (BRASIL, 1988).

3 “Art. 200. Ao sistema único de saúde compete, além de outras atribuições, nos termos da lei: [...] VIII - colaborar na proteção do meio ambiente, nele compreendido o do trabalho" (BRASIL, 1988). 
Não se trata apenas de um mero direito trabalhista relativo ao contrato de trabalho, posto que busca assegurar a saúde e a segurança física e psíquica do trabalhador enquanto membro da sociedade. Ou seja, trata-se de um direito da sociedade como um todo e não apenas do trabalhador, eis que seu não cumprimento resulta em prejuízo a todos e não apenas a ele. Ao contrário do direito do trabalho, que regulamenta o contrato de trabalho propriamente, o direito ao meio ambiente do trabalho está vinculado à saúde do trabalhador como cidadão (MELO, 2013). O meio ambiente do trabalho pode ser conceituado como

[...] o local onde as pessoas desempenham suas atividades laborais, sejam remuneradas ou não, cujo equilíbrio está baseado na salubridade do meio e na ausência de agentes que comprometam a incolumidade físico-psíquica dos trabalhadores, independente da condição que ostentem (homens ou mulheres, maiores ou menores de idade, celetistas, servidores públicos, autônomos etc.) (FIORILLO, 2013, p. 22-23).

O artigo 157 da Consolidação das Leis do Trabalho (CLT) preconiza que cabe às empresas “[...] cumprir e fazer cumprir as normas de segurança e medicina do trabalho; instruir os empregados, através de ordens de serviço, quanto às precauções a tomar no sentido de evitar acidentes do trabalho ou doenças ocupacionais [...]” (BRASIL, 1943).

As normas de saúde, higiene e segurança do trabalho, relativas ao meio ambiente do trabalho saudável trata-se de normas de ordem pública e não normas de direito privado, em que pese integrarem também o próprio contrato de trabalho (MELO, 2013). A salubridade no ambiente do trabalho, ou melhor, a saúde no trabalho, não diz respeito tão somente à inexistência de doenças, mas sim a uma série de condições que efetivamente constroem um ambiente do trabalho saudável, ressaltando-se que não se está referindo apenas ao local de trabalho, ainda que este seja o mais relevante à primeira vista, mas também da própria natureza do trabalho (ROCHA, 2013). 
Importante salientar, dessa forma, que pesquisas recentes mostram que o passar dos anos e a evolução tecnológica não estão atenuando os riscos decorrentes do meio ambiente de trabalho insalubre. Ao contrário, o que ocorre é uma intensificação de ocorrências de acidentes do trabalho e, em especial, doenças ocupacionais. A Organização Internacional do Trabalho (OIT), no ano de 2013, lançou um relatório como espécie de alerta ao mundo, no qual aponta que as doenças profissionais são responsáveis por seis vezes mais mortes do que acidentes do trabalho, destacando-se que por ano ocorrem 160 milhões de casos de doenças ligadas à atividade profissional não letais. Assim, estima que 2,34 milhões de pessoas morram todos os anos em decorrência de doenças profissionais e acidentes do trabalho, e, desse número, 2,02 milhões são decorrentes de doenças do trabalho (ORGANIZAÇÃO..., 2013). Apesar disso, não existem fortes tendências a buscar uma redução desses números, o que poderia começar com a simples “[...] monitorização regular do ambiente de trabalho e a vigilância médica dos trabalhadores [...]” (ORGANIZAÇÃO..., 2013, p. 7).

Destarte, é certo que o mundo do trabalho não é um complexo estanque, pois está em constante mutação e as relações de trabalho continuam a sofrer alterações. Portanto, a noção de meio ambiente do trabalho não é imutável, ou seja, está em constante movimento para acompanhar o desenvolvimento do paradigma do mundo do trabalho, que por sua vez, acompanha o desenvolvimento da própria sociedade (ROCHA, 2013). Conforme ensina Rocha, “[...] importante é notar que o meio ambiente é uno, a realização do trabalho humano qualifica-o” (ROCHA, 2013, p. 103). Ou seja, não existe um meio ambiente do trabalho sem o trabalhador. "Conclui-se que a proteção indicada não pretende reparar um dano eventualmente sofrido pelo trabalhador quando existentes situações inseguras no ambiente do trabalho. Vai além, é preventiva, estendendo-se à ameaça dessa lesão” (SANCHEZ, 2009, p. 34). 
Feita essa análise preliminar acerca do meio ambiente do trabalho, passa-se ao estudo mais específico sobre o avanço das nanotecnologias e suas incertezas.

\section{O DIREITO AO MEIO AMBIENTE DO TRABALHO SAUDÁVEL E AS (IN)CERTEZAS DAS NANOTECNOLOGIAS}

Quando se está a falar em meio ambiente do trabalho, não basta mencionar pagamento por eventuais danos causados, pois estes, via de regra, são irreversíveis ou irreparáveis. É de extrema importância, portanto, o agir antes que o dano ocorra (GEMIGNANI; GEMIGNANI, 2012). Cada vez mais o ambiente de trabalho tem impacto direto na vida da sociedade. Na verdade,

[...] o sofrimento no trabalho não foi extinto nem sequer atenuado com a automação (mecanização e robotização) da produção. Pelo contrário, trabalhadores continuam sendo expostos a malefícios de toda ordem, como, por exemplo, a agentes agressivos, como amianto, benzeno; a imposições severas na organização do trabalho; e ao receio constante do desligamento do posto de trabalho (ROCHA, 2013, p. 117).

A perspectiva atual mostra que não existe um efetivo padrão que garanta a salubridade do ambiente do trabalho (ROCHA, 2013). Nessa linha estão as nanotecnologias, que nada mais são do que uma das mais, senão a mais, fantástica inovação da tecnologia da atualidade. Leigos no assunto nem sabem que essa inovação tecnológica existe, mas pelos estudiosos ela já está sendo considerada a $5^{\text {a }}$ revolução industrial (BARTH, 2006). Isso ocorre também em razão da rápida e infinita evolução da humanidade, principalmente no tocante a novas tecnologias. Por serem novas e, por conseguinte, desconhecidas, geram riscos desconhecidos em especial no tocante ao direito do trabalho, posto que é o trabalhador que está exposto diretamente ao contato com situações e produtos incógnitos. 


\title{
3.10 que são nanotecnologias?
}

As nanotecnologias nada mais são do que resultado do avanço tecnológico produzido e esperado pela humanidade. Significa a possibilidade de manusear o invisível. Quanto se está a falar em nanotecnologias, a primeira pergunta que se faz é: O que são nanotecnologias? "O termo 'nano' representa uma medida e equivale à bilionésima parte de um metro, isto é, ao se dividir um metro por um bilhão de vezes, chega-se ao nanômetro" (ENGELMANN, 2014b, p. 339-340). Dessa forma, "Por meio do termo 'nanotecnologias' fica caracterizada a possibilidade de variadas produções tecnológicas na escala nanométrica. Vale dizer, representam uma alternativa de manipular átomos e moléculas na bilionésima parte do metro" (ENGELMANN, 2013c, p. 301). Assim,

\begin{abstract}
A nanotecnologia é o conjunto de ações de pesquisa, desenvolvimento e inovação que é obtida graças às especiais propriedades da matéria organizada a partir de estruturas de dimensões nanométricas. Atualmente existe uma necessidade de alerta do direito no que se refere aos riscos à saúde do trabalhador decorrentes da aplicação das nanotecnologias em escala industrial (OSHIRO; HOHENDORFF; ENGELMANN, 2013, p. 669).
\end{abstract}

Hodiernamente a produção com nanotecnologias está em ritmo acelerado. "Exemplificativamente, podem-se mencionar alguns produtos e setores que atualmente já trabalham a elaboração de produtos na nanoescala: protetores solares, calçados, telefones celulares, tecidos, cosméticos, [...]” (ENGELMANN, 2013, p. 302), sendo que tudo, é claro, passa pelas mãos do trabalhador. A partir daí é que surgem os problemas relativos aos trabalhadores que mantêm contato com essa nova tecnologia, posto que “[...] na escala nano o comportamento dos átomos e moléculas diferem, produzindo reações muitas vezes desconhecidas" (ENGELMANN, 2011a, p. 28). Cita-se como exemplo o caso das sete jovens chinesas que trabalhavam em uma fábrica de tintas que utilizava nanopartículas em sua fórmula. Após meses laborando e inalando as nanopartículas, duas jovens morreram e as outras sofreram danos permanentes nos pulmões (ESTADÃO, 2009). 
Engelmann refere ainda que "A imprevisibilidade das transformações geradas nas nanopartículas a partir do momento em que elas ingressam no meio ambiente representa uma característica muito forte" (ENGELMANN, 2013, p. 305). Enfim, o presente estudo irá se ater à noção de que as nanotecnologias são aquelas que trabalham com escala nanoscópica, necessariamente intencional, ou seja, aquelas desenvolvidas propositadamente pelo homem, sobre as quais não temos qualquer parâmetro anterior.

Atualmente existem inúmeras formas de aplicação de nanotecnologias já utilizadas no mercado, “[...] amianto, CFCs, o DDT, a gasolina com chumbo, mercúrio e várias outras antigas substâncias e tecnologias 'maravilha', alguns nanomateriais, sem dúvida, terão consequências negativas significativas e inesperadas sobre a saúde humana e o meio ambiente" (KIMBRELL, 2009, p. 15, tradução nossa). Estudos mais recentes mostram que "O mercado de produtos de consumo tem atualmente mais de mil produtos contendo nanomateriais, incluindo maquiagem, protetor solar, armazenamento de alimentos, produtos, equipamentos, roupas, eletrônicos, computadores, artigos esportivos, e revestimentos" (NATIONAL..., 2013a, p. IV, tradução nossa).

Assim sendo, "Se os nossos decisores políticos vão esperar até que ocorra uma tragédia ou adaptar preventivamente ainda não se sabe" (tradução nossa) (KIMBRELL, 2009, p. 15).

Dessa forma, podemos concluir que os riscos existem, basta encontrarmos a melhor forma de preveni-los e nos protegermos para no futuro podermos continuar essa enorme evolução tecnológica.

\subsection{Os riscos ao trabalhador decorrentes das nanotecnologias}

O trabalho é um dos instrumentos mais efetivos de garantia da dignidade da pessoa humana, daí a importância de relacioná-lo diretamente a uma efetiva proteção contra os riscos do meio ambiente do trabalho insalubre. Estimativas determinam que em 2020 as nanotecnologias proporcionarão um impacto de três trilhões de dólares na economia global, 
empregando cerca de seis milhões de trabalhadores no manuseio desses nanomateriais, representando um grande desafio para a compreensão, visão e gestão de riscos potenciais à saúde dos trabalhadores (NATIONAL..., 2013b).

Nesse sentido, importante se faz estudar os riscos decorrentes das nanotecnologias no ambiente do trabalho, pois por certo que os trabalhadores são os principais prejudicados, na medida em que são os destinatários primeiros dos efeitos dessa nova tecnologia, tanto na questão da produção quanto na sua utilização como ferramenta de trabalho (GÓES; ENGELMANN, 2015).

Assim, “[...] estudos ratificam a necessidade de um crescente cuidado com a saúde e a segurança do ser humano e a atenção com o meio ambiente" (ENGELMANN, 2013, p. 306), posto que "As respostas obtidas das ciências exatas, até o momento, são provisórias, e não conclusivas, mas com evidência de riscos" (ENGELMANN, 2013, p. 306). Sendo assim, apesar de atualmente nos deslumbrarmos com o grande leque de benefícios que a nanotecnologia irá nos trazer não podemos nos deixar levar e colocar de lado possíveis resultados indesejados decorrentes dessa nova tecnologia (OSHIRO; HOHENDORFF; ENGELMANN, 2013). Isso porque,

O conhecimento das características das substâncias em tamanho maior não fornece informações compreensíveis sobre suas propriedades no nível nano, uma vez que as mesmas propriedades que alteram as características físicos e químicas das nanopartículas podem também provocar consequências não pretendidas e desconhecidas quando em contato com o organismo humano. (OSHIRO; HOHENDORFF; ENGELMANN, 2013, p. 670).

Existem duas preocupações no tocante às nanotecnologias que clamam mais atenção: a primeira diz respeito aos efeitos biológicos e químicos das nanopartículas em contato com o corpo humano ou o ecossistema; a segunda 
levanta a questão dos níveis de circulação e concentração de nanopartículas no ambiente (UNITED..., 2007). Diante dessas considerações podemos concluir que a inserção das nanotecnologias no ambiente de trabalho coloca em risco a efetiva proteção ao trabalhador, visto que, consoante já exposto, não se sabe quais são suas características, seus efeitos e riscos. Apesar disso, “A área jurídica continua imersa numa tradicional 'tranquilidade' de enfrentamento dos novos direitos e deveres que surgem diariamente" (OSHIRO; HOHENDORFF; ENGELMANN, 2013, p. 669).

Na prática, o debate acerca das nanotecnologias no ambiente de trabalho é quase nulo, mas já pode ser percebido em alguns lugares, como na convenção coletiva entre o Sindicato da Indústria de Produtos Farmacêuticos no Estado de São Paulo e o Sindicato dos Trabalhadores nas Indústrias Químicas, Farmacêuticas, Plásticas, de Explosivos, Abrasivos, Fertilizantes e Lubrificantes de Osasco e Cotia, ambos do Estado de São Paulo, na qual restou ajustado o seguinte:

Saúde e Segurança do Trabalhador

\section{Condições de Ambiente de Trabalho}

\section{CLÁUSULA OITAVA - NANOTECNOLOGIA}

A empresa garantirá que os membros da Cipa e do SESMT sejam informados quando da utilização de nanotecnologia no processo industrial. A Cipa, o SESMT e os trabalhadores terão ainda acesso a informações sobre riscos existentes à sua saúde e as medidas de proteção a adotar (SINDICATO DA INDÚSTRIA DE PRODUTOS FARMACÊUTICOS NO ESTADO DE SÃO PAULO (SINDUSFARMA); SINDICATO DOS TRABALHADORES NAS INDÚSTRIAS QUÍMICAS, FARMACÊUTICAS, PLÁSTICAS, DE EXPLOSIVOS, ABRASIVOS, FERTILIZANTES E LUBRIFICANTES DE OSASCO E COTIA, 2012, p. 6, grifo do autor).

Assim, coloca-se em pauta o princípio da precaução, que deverá ser aplicado no tocante aos riscos criados pelas nanotecnologias, posto que essas devem gerar desenvolvimento e nunca danos à saúde, em especial do trabalhador, permitindo, assim, uma evolução saudável (OSHIRO; HOHENDORFF; ENGELMANN, 2013). 
Dito isso, passa-se à análise do princípio da precaução aplicado ao direito do trabalho por meio da ferramenta da árvore de decisão, como meio de precaver possíveis malefícios ao meio ambiente do trabalho causados pelas nanotecnologias.

\section{PRINCÍPIO DA PRECAUÇÃO E ÁRVORE DE DECISÃO: Em busca de respostas jurídicas apropriadas aos novos direitos e deveres decorrentes das nanotecnologias}

Observa-se que o passar dos anos trouxe, especialmente a partir da constitucionalização dos direitos sociais, o surgimento de normas atinentes à saúde e segurança do trabalhador, principalmente pelo estabelecimento de padrões de conduta e regras mínimas. É cediço que o Direito não tutela fatos futuros dos quais não se tem qualquer conhecimento, ou seja, "A estrutura e o funcionamento do Direito sempre buscavam fatos ocorridos no passado, que são juridicizados no presente, a fim de se regular o futuro" (ENGELMANN, 2013, p. 307). Esse é o dilema atual no tocante às nanotecnologias, posto que, na verdade, não se sabe quais riscos e prejuízos poderá, grifa-se, poderá causar para a sociedade, mais especificamente aqui ao trabalhador que mantenha contato com elas.

Está-se a fazer, portanto, também, uma crítica ao modelo de norma de Hans Kelsen, na medida em que este tem como fundamento buscar fatos que ocorreram no passado, para regulamentar o futuro. Tal modelo mostra-se totalmente insuficiente para suprir as necessidades e constantes mudanças nas quais a sociedade atual está fundamentada.

Evidentemente que "[...] a evolução das técnicas acarreta transformações do Direito: era preciso que nascesse a informática para que se preocupasse em legislar sobre a informática e as liberdades...” (SUPIOT, 2007, p. 139). Essas transformações, contudo, ocorrem de forma retardada, posterior ao surgimento da questão a que se regulamenta na sociedade. $\mathrm{Ou}$ 
seja, primeiro deve ocorrer o fato na sociedade para que, posteriormente, $o$ Direito passe a regulamentá-lo. Ocorre que as necessidades atuais da sociedade são diferentes, a imediatidade é medida que se impõe, em especial no que toca à saúde e segurança das pessoas.

Nesse sentido, interessante citar Mireille Delmas-Marty quando refere que "Ao vermos a profusão de normas que embaralham a nossa imagem da ordem jurídica, sentimos a necessidade de um direito comum, em todos os sentidos do termo" (DELMAS-MARTY, 2004, p. IX). Delmas-Marty propõe o que ela chama de um Direito comum, ou seja, "Um direito acessível a todos, que não seria imposto de cima como verdade revelada, pertencente apenas aos intérpretes oficiais, mas consagrado de baixo como verdade compartilhada, portanto relativa e evolutiva [...]”(DELMAS-MARTY, 2004, p. XI), um direito “[...] comum igualmente a diferentes setores do direito para assegurar a coerência de cada sistema, apesar da especialização crescente das regras [...]” (2004, p. XI).

No mesmo sentido Alain Supiot defende uma teoria da regulação (o que equivale à regulação não tradicional ou não estatal), pois acredita que a chave para o equilíbrio é a esfera coletiva do Direito do Trabalho. Fazer com que os institutos já existentes cumpram cada qual seu devido papel é fundamental. Essa é a proposta de Supiot, na medida em que reconhece a importância do direito coletivo na prática do Direito do Trabalho. O Direito do Trabalho, portanto, sendo um direito diferenciado, deve operar de acordo com uma ruptura com os pressupostos tradicionais, a fim de se libertar das amarras do paradigma tradicional do Direito, que, em verdade, mais aprisiona do que protege (SUPIOT, 1996).

Assim sendo, deve ocorrer uma ruptura com a estrutura do Direito, na qual o Estado deve regulamentar padrões gerais mínimos e inflexíveis e o direito coletivo regular as questões específicas. A regulamentação e a regulação se complementam, não se excluem (cooperação entre as esferas pública e privada). Então surge a questão: O que, na relação de trabalho, 
deve ser regulamentada pelo Direito (lei), e o que deve ser deixado para a regulação social, ou seja, outras formas de regulação? Para Supiot, “[...] apenas uma regulação adequada, e não uma regulamentação rígida, pode proteger a sociedade da desordem entrópica [...]” (2007, p. 159). Ambas (regulamentação e regulação) devem operar conjuntamente e de forma coordenada, na medida em que o Estado/lei deve fixar parâmetros mínimos (princípios e objetivos) e o direito coletivo aplica esses princípios e objetivos adaptando-os à realidade de cada trabalhador.

Dessa forma, a fim de não deixarmos esse desconhecimento acerca de potenciais riscos à saúde humana ao simples acaso, o Direito deve encontrar um meio de prever possíveis riscos decorrentes das nanotecnologias, utilizando-se, de início, da ferramenta da árvore de decisão como fundamento para estimular a aplicação do princípio da precaução nas relações de trabalho em que se utiliza nanotecnologias pela mão de obra do trabalhador.

\subsection{O princípio da precaução}

Ao contrário da prevenção, que está vinculada aos riscos conhecidos, a precaução está ligada aos riscos desconhecidos e futuros (GÓES; ENGELMANN, 2015). O princípio da precaução “[...] impõe prioritariamente e antecipadamente a adoção de medidas preventivas e justifica a aplicação de outros princípios, como o da responsabilização e da utilização das melhores tecnologias disponíveis" (CANOTILHO, 2012, p. 29). Determina que quando houver dúvida sobre a salubridade de uma determinada atividade para o meio ambiente, deve-se sempre decidir em favor do meio ambiente. Ocorre, portanto, uma espécie de inversão do ônus da prova, ou seja, quem deverá provar que a atividade em questão é salubre e não produzirá riscos ao meio ambiente é aquele que quer se valer dessa atividade (CANOTILHO, 2012). 
A precaução permite um agir ainda que não se tenha conhecimento do dano que se corre ou do risco que estamos tentando evitar (CANOTILHO, 2012), exatamente o que o Direito do Trabalho está passando com a inserção das nanotecnologias no mundo do trabalhador. É claro que existe sério “[...] conflito entre a certeza e a segurança jurídicas, por um lado, e a evolução científica, o progresso social e o desenvolvimento econômico, por outro" (CANOTILHO, 2012, p. 64). Nesse sentido, a aplicação do princípio da precaução visa a

[...] equacionar a possibilidade do surgimento de perigo de dano grave ou irreversível e a inexistência de certeza quanto ao efetivo controle científico das consequiências da pesquisa em relação ao meio ambiente e também ao ser humano. Esses são os parâmetros do princípio da precaução (WEYERMÜLLER; FLORES; ENGELMANN, 2010, p. 125).

Mostra-se, assim, plenamente aplicável o princípio da precaução no Direito do Trabalho, com vistas a preservar o meio ambiente do trabalho saudável, em razão da inserção de nanotecnologias no meio laboral. No cenário do movimento do diálogo entre as fontes do Direito se poderá operar o movimento que leva o princípio da precaução (meio ambiente em geral) ao princípio protetor do trabalhador (meio ambiente do trabalho) visando a garantir a dignidade da pessoa humana do trabalhador (HOHENDORFF; COIMBRA; ENGELMANN, 2016, p. 157).

\subsection{A árvore de decisão como ferramenta para a aplicação do princípio da precaução na busca de respostas jurídicas apropriadas aos novos direitos e deveres decorrentes das nanotecnologias}

Conforme já analisamos nos tópicos anteriores, o meio ambiente do trabalho é aquele que compreende as condições internas e externas do local onde se dá a prestação laboral, tendo relação direta com a saúde dos 
trabalhadores, sendo, portanto, um direito fundamental do trabalhador, na medida em que deve ser compatível com a condição de pessoa humana (OSHIRO; HOHENDORFF; ENGELMANN, 2013). De tal modo,

No meio ambiente do trabalho a aplicação do princípio da precaução é encontrada em todas as situações de incerteza sobre a potencialidade danosa de determinado produto químico ou biológico cujo conhecimento sobre possíveis efeitos toxicológicos sobre a saúde humana e o meio ambiente ainda é precário (OSHIRO; HOHENDORFF; ENGELMANN, 2013, p. 673-674).

As nanotecnologias inseridas no meio ambiente do trabalho são uma incógnita, posto que o Direito ainda não se estruturou adequadamente a fim de responder aos desafios propostos por essa inovação tecnológica (OSHIRO; HOHENDORFF; ENGELMANN, 2013). É cediço que o Direito, em termos vulgares, não acompanha a evolução das relações humanas, mas tão somente busca regulamenta-las após sua existência. Não é de hoje que o princípio da precaução tem sido utilizado no Direito do Trabalho para regrar as atividades de risco.

Interessante citar, entretanto, uma recente decisão da Sessão Especializada em Dissídios Coletivos do Tribunal Regional do Trabalho da Décima Quinta Região (Campinas/SP), que, ao julgar o dissídio coletivo de n. 000615186.2013.5.15.0000 (DC), no qual foi suscitante o Sindicato dos Trabalhadores nas Indústrias da Fabricação do Álcool, Etanol, Bietanol, Biocombustível, Químicas e Farmacêuticas de Ribeirão Preto e Região, proferiu a seguinte decisão acerca do uso das nanotecnologias pela empresa suscitada:

\section{$[\ldots]$}

CLÁUSULA 84 $4^{\mathrm{a}}$ - NANOTECNOLOGIA As empresas são obrigadas a informar a entidade sindical sobre o uso de nanotecnologia no processo industrial e no ambiente de trabalho. No uso de nanotecnologia serão tomadas as devidas providências de proteção e monitoramento da saúde dos trabalhadores. Iniciar processo de informação ampla sobre 
os conceitos básicos de nanotecnologias: o que é, a importância, os possíveis usos e as incertezas; Utilizar os espaços de comunicação nas Sipats, encontros anuais, comunicação visual e virtual sobre o tema; Transmitir informações específicas quando do início do uso de nanocompósitos na fabricação de fármacos, respeitando o Direito de Saber. Divulgar aos trabalhadores informações sobre as substâncias e suas particularidades quando em escala nanométrica, medidas de verificação de vazamentos e/ou contaminações, medidas de primeiros socorros, estratégias de prevenção e monitoramento da saúde; As empresas que optarem por utilizar nanotecnologias destinarão recursos para pesquisa sobre as consequências e medidas de proteção ao trabalhador equiparadas aos recursos destinados à pesquisa de produtos; Obedecer ao princípio da precaução: adoção de medidas que devem ser implantadas visando prevenir danos à saúde dos trabalhadores, mesmo na ausência da certeza científica formal da existência do risco grave ou irreversivel e de suas consequências à saúde; Estabelecer sistema de proteção coletiva eficaz; Estabelecer medidas especificas no PPRA e PCMSO para os trabalhadores expostos a nanocompósitos; A empresa garantirá que os membros da Cipa e do SESMT sejam informados quando da utilização de nanotecnologia no processo industrial. A Cipa, o SESMT e os trabalhadores terão ainda acesso a informações sobre riscos existentes à sua saúde e as medidas de proteção a adotar [...] (BRASIL, 2014).

Como é possível perceber, o dissídio coletivo revela a total incerteza da utilização das nanotecnologias no ambiente de trabalho, preocupando-se em determinar a precaução de possíveis riscos delas decorrentes, utilizando-se, para tanto, do princípio da precaução. "Uma nova tecnologia fruto da grande revolução tecnológica atual também precisa de um novo modo, meio de regulamentação, diferente do tradicional e letárgico modelo de regulamentação legal (por meio de leis)" (OSHIRO; HOHENDORFF; ENGELMANN, 2013, p. 677). Assim sendo,

[...] a lei terá cada vez menos condições de previsibilidade - especialmente pelo fato de sempre olhar para trás e transformar em jurídicos fatos do passado e dentro de um compasso de tempo incompatível com o tempo da inovação das nanotecnologias (ENGELMANN, 2011b, p. 351). 
Dessa forma, o desafio imposto aos juristas "[...] exige respostas quanto ao estabelecimento de limites e para a solução de conflitos que venham a surgir" (OSHIRO; HOHENDORFF; ENGELMANN, 2013, p. 677). Assim, mostrando-se a lei incapaz de prever todos os desafios decorrentes da instalação das novas tecnologias, em especial das nanotecnologias, temos de buscar alternativas como o pluralismo de fontes (OSHIRO; HOHENDORFF; ENGELMANN, 2013). É certo que “[...] a lei é incapaz de prever todos os casos concretos, mas isso não significa que as situações não previstas deixam de reclamar uma solução conforme o direito" (OSHIRO; HOHENDORFF; ENGELMANN, 2013, p. 677). Além disso, segundo Engelmann, “[...] é preciso perguntar como regular, o que regular e por que regular. Será que é a lei que tem de regular isso? Às vezes a lei é o problema, ela congela a realidade" (HOHENDORFF; ENGELMANN, 2014, p. 131).

No decorrer do trabalho deparamo-nos com a insuficiência/letargia do Direito no tocante às nanotecnologias. Sendo assim, "A gestão dos riscos gerados pelas nanotecnologias precisará ser apreendida pelo Direito a partir dos aportes trazidos de outras áreas do conhecimento, por exemplo, a Administração" (HOHENDORFF; ENGELMANN, 2014, p. 163). Na Administração, quando é necessário tomar uma decisão de acordo com uma gama de alternativas, isso significa a renúncia das demais, criando-se novas alternativas a partir da decisão tomada. Essa escolha de alternativas é chamada de árvore de decisão (HOHENDORFF; ENGELMANN, 2014). Segundo Chiavenato, “Árvore de decisão é uma técnica para facilitar como as decisões sob condições de risco devem ser tomadas e onde é possível atribuir valores e ganhos ou perdas em cada alternativa" (2003, p. 470). Com o auxílio do método da árvore de decisão pode-se buscar a aplicação do princípio da precaução. Uma árvore de decisão (técnica utilizada pela Administração) nada mais é do que “[...] um algoritmo gráfico que funciona como uma ferramenta de apoio à tomada de decisão, sendo que a sua principal vantagem é a possibilidade de decompor um problema complexo em vários subproblemas mais simples" (HOHENDORFF; ENGELMANN, 2015, p. 7, tradução nossa). Árvore de decisão, portanto, é a escolha de 
um meio alternativo em detrimento de outros meios, seguido do surgimento de novas alternativas e assim sucessivamente. Não significa, entretanto, a solução completa para os objetivos, mas sim a melhor solução encontrada no momento da tomada de decisão (HOHENDORFF; ENGELMANN, 2015). "Para efetuar a representação gráfica da árvore de decisão são geralmente usadas linhas para identificar a decisão (por exemplo 'sim' ou 'não') e nós para identificar as questões sobre as quais se deve decidir" (NUNES, 2015). Assim, “Cada um dos ramos formado por linhas e nós termina numa espécie de folha que identifica a consequência mais provável da sequência de decisões tomadas" (NUNES, 2015).

Sendo assim, "Partindo da raiz, a cada nó de decisão o resultado do teste de decisão é determinado e inicia-se o processo pela raiz da sub-árvore correspondente a esse resultado" (HOHENDORFF; ENGELMANN, 2014, p. 164). " "A árvore de decisão contém pontos de decisão em que determinamos, com base nos resultados observados em etapas anteriores e nas expectativas do que pode ocorrer no futuro, qual a melhor linha de ação a tomar" (DAMODARAN, 2009, p. 162).

\footnotetext{
4 "Para ilustrar o funcionamento básico de uma árvore de decisão, pode ser considerado novamente o problema de diagnosticar pacientes [...]. Suponha que um novo paciente chegue ao consultório do médico. Como o médico poderia diagnosticar o paciente? A primeira pergunta que pode ser feita ao paciente é se ele tem sentido dor (corresponderia ao nó-raiz da árvore de decisão). A seguir, outras perguntas podem ser feitas, dependendo da resposta obtida. Por exemplo, se o paciente está tendo febre ou enjoos, ou ainda se tem notado alguma mancha no corpo. O exemplo anterior apresenta uma forma de solucionar um problema de classificação por meio de uma sequência de perguntas sobre uma série de características de um objeto (no caso, um paciente). Uma vez obtida a resposta àquela pergunta, outra pode ser realizada até que se chegue a uma conclusão sobre a classe a que pertence o objeto. Essa sequência de perguntas e suas possíveis respostas podem ser organizadas na forma de uma árvore de decisão, a qual é uma estrutura hierárquica composta por nós e arestas. Dessa forma, é possível utilizar uma árvore de decisão para classificar um novo paciente como saudável ou doente. Para isso, basta partir do nó raiz da árvore e ir percorrendo-a, através das respostas aos testes dos nós internos, até chegar em um nó folha, o qual indica a classe correspondente do novo paciente. Além da obtenção da classe, a grande vantagem é que a trajetória percorrida até o nó folha representa uma regra, facilitando a interpretabilidade do modelo pelo usuário, no caso um médico" (ZUBEN; ATTUX, 2016, p. 11-12).
} 
Trata-se, portanto, de uma técnica de grande importância e muito utilizada em problemas nos quais há a necessidade de escolhas que envolvam riscos futuros, como é o caso das nanotecnologias. É uma ferramenta que pode ser utilizada para analisar as informações necessárias na avaliação dos riscos envolvendo as nanopartículas, com vistas a garantir a segurança da saúde humana e do meio ambiente, em especial. Basta, portanto, que se iniciem pesquisas, por meio de coletas de informações acerca de cada tipo de nanotecnologia empregada em cada produto a ser analisado, informações estas que serão necessárias para a construção de conhecimento acerca da área (HOHENDORFF; ENGELMANN, 2015).

Para a utilização da arvore de decisão na análise de nanotecnologias, por exemplo, deve-se iniciar identificando que tipo de nanopartícula será analisada, tendo em vista que as nanotecnologias possuem diversas variações, como tamanho e número de partículas. O tamanho e o número de nanopartículas podem alterar completamente a análise de um produto. Após essa definição é necessário determinar a utilização do produto (HOHENDORFF; ENGELMANN, 2014).

Mediante a utilização da ferramenta da árvore de decisão, portanto, juntamente com a aplicação do princípio da precaução, podemos estabelecer a realização de estudos mais específicos e prolongados para que se tenha um mínimo de dados confiáveis acerca de possíveis riscos decorrentes de cada nanotecnologia existente.

As pesquisas sobre os impactos das nanoparticulas no meio ambiente estão apenas no início e é o caso de se aplicar o princípio da precaução e exigir que sejam desenvolvidas de forma concomitante pesquisas que levem a inovações tecnológicas advindas da nanotecnologia e a pesquisas toxicológicas devido ao uso e disposição destas nanoparticulas nos ecossistemas naturais (OSHIRO; HOHENDORFF; ENGELMANN, 2013, p. 672-673). 
Sendo assim, "O princípio da precaução deve fazer parte da esfera civil do século XXI, mas de forma equilibrada e sem perder de vista os princípios de razoabilidade e de proporcionalidade” (2013, p. 673). Ou seja, a precaução deverá ser seguida em razão das incertezas científicas decorrentes das novas tecnologias que se expandem em alta velocidade, em especial as nanotecnologias.

\section{CONCLUSÃO}

Ao final do presente estudo conclui-se que o meio ambiente do trabalho é direito fundamental de todo trabalhador, eis que está diretamente relacionado à dignidade da pessoa humana. Essa concepção não é recente, pois ela vem sendo desenvolvida ao longo de muitos anos, principalmente a partir da Revolução Industrial ocorrida no século 18. Conforme é possível observar, a questão tem grande impacto na sociedade. Em que pese o meio ambiente do trabalho não se resumir somente a acidentes do trabalho e doenças ocupacionais, o número de mortes de trabalhadores envolvendo principalmente doenças ocupacionais é muito alto, o que revela o total descaso com que é tratado o trabalhador.

Nesse sentido, as nanotecnologias estão sendo chamadas de $5^{\mathrm{a}}$ Revolução Industrial e, apesar de não serem amplamente conhecidas pela sociedade, como pudemos observar, já possuem grande utilização em diversas áreas e produtos, como cosméticos, tecidos, calçados, etc. Esse, portanto, é um dos grandes problemas das nanotecnologias, ou seja, muitos nem sabem que estão mantendo contato com partículas nano. Ademais, a inexistência de pesquisas mais aprofundadas acerca dos malefícios que essa nova tecnologia pode trazer à saúde humana também é uma das principais preocupações em pauta, uma vez que estamos nos referindo a um meio ambiente do trabalho saudável. 
Assim, consoante analisado, a sua utilização enseja no mínimo dúvida acerca da salubridade ou insalubridade do meio ambiente laboral em que está inserida. Sendo assim, importante, pois, uma análise com vistas à necessária utilização do princípio da precaução, posto que este permite um agir ainda que não se saiba da existência de um determinado dano. Importante salientar que o Direito não está estruturado adequadamente para tutelar possíveis danos futuros, mas estes não podem ser deixados de lado num primeiro momento, mas sim devem ser colocados em primeiro plano. Dessa forma, como pudemos perceber, a tutela jurídica tradicional, ou seja, por meio de leis, não dará conta de abranger as necessidades que as nanotecnologias estão trazendo para a sociedade. Devemos compreender que a sociedade está em constante mudança e o Direito deve sempre buscar alcançá-la, para que possa, efetivamente, corresponder ao seu papel principal.

Destarte, a ferramenta da árvore de decisão e o princípio da precaução correspondem a essa atual necessidade da sociedade, posto que, no que diz respeito às novas tecnologias, em especial às nanotecnologias, podemos estabelecer a realização de estudos mais específicos e prolongados para que se tenha um mínimo de dados confiáveis acerca de possíveis riscos decorrentes das nanotecnologias. Por fim, conclui-se que a precaução deverá ser seguida em razão das incertezas científicas decorrentes das novas tecnologias que se expandem em alta velocidade, em especial as nanotecnologias.

\section{REFERÊNCIAS}

BARTH, Wilmar Luiz. Nanotecnologia: “há muito espaço lá embaixo!”. In: Revistas Eletrônicas da PUCRS. Porto Alegre, v. 36, n. 153, set. 2006. Disponível em: <http://revistaseletronicas.pucrs.br/ojs/index.php/teo/article/ view/1754/1287>. Acesso em: 11 set. 2016. 
BRASIL. Constituição (1988). Constituição da República Federativa do Brasil de 1988. Disponível em: <http://www.planalto.gov.br/ccivil_03/constituicao/ constituicao.htm>. Acesso em: 11 set. 2016.

. Decreto - Lei no 5.452 , de $1^{\circ}$ de maio de 1943. Aprova a Consolidação das Leis do Trabalho. Disponível em: <http://www.planalto.gov.br/ccivil_03/ decreto-lei/del5452.htm>. Acesso em: 11 set. 2016.

. Lei $\mathrm{n}^{\circ}$ 6.938, de 31 de agosto de 1981. Dispõe sobre a Política Nacional do Meio Ambiente, seus fins e mecanismos de formulação e aplicação, e dá outras providências. Disponível em: <http://www.planalto.gov.br/ccivil_03/leis/16938compilada.htm>. Acesso em: 11 set. 2016.

. Tribunal Regional do Trabalho da $15^{\mathrm{a}}$ Região. Dissídio Coletivo de Natureza Econômica nº 0006151-86.2013.5.15.0000, Seção de Dissídios Coletivos. Suscitante: Sindicato dos Trabalhadores nas Indústrias da Fabricação do Álcool, Etanol, Bioetanol, Biocombustível, Químicas e Farmacêuticas de Ribeirão Preto e Região. Suscitado: Ldc Serv Biosev Bioenergia S.A. Relator Desembargador: Adriene Sidnei de Moura David Diamantino. Campinas, 12 de fevereiro de 2014. Disponível em: <http://busca.trt15.jus.br/search?q=cache:zYGKa7vD10sJ:g rumari.trt15.jus.br:1111/doc/249846+Diss\%C3\%ADdio+Coletivo+de+Nature $\mathrm{za}+\mathrm{Econ} \% \mathrm{C} 3 \% \mathrm{~B} 4 \mathrm{mica}+\mathrm{n} \% \mathrm{C} 2 \% \mathrm{BA}+0006151-86.2013 .5 .15 .0000 \&$ site=jurisp\&cl ient=dev_index\&output=xml_no_dtd\&proxystylesheet=dev_index\&ie=UTF-8\&1r=lang_pt\&access=p\&oe=UTF-8>. Acesso em: 11 set. 2016.

CANOTILHO, José Joaquim Gomes. Parte I - direito constitucional ambiental português e da União Europeia. In: CANOTILHO, José Joaquim Gomes; LEITE, José Rubens Morato (Org.). Direito constitucional ambiental brasileiro. 5. ed. rev. São Paulo: Saraiva, 2012.

CHIAVENATO, Idalberto. Introdução à teoria geral da administração: uma visão abrangente da moderna administração das organizações. 7. ed. rev. e atual. Rio de Janeiro: Elsevier, 2003.

DAMODARAN, Aswath. Gestão estratégica do risco: uma referência para a tomada de riscos empresariais. Tradução Felix Nonnenmacher. Porto Alegre: Bookman, 2009. (Livro eletrônico). 
DELMAS-MARTY, Mireille. Por um direito comum. Tradução Maria Ermantina de Almeida Prado Galvão. São Paulo: Martins Fontes, 2004.

ENGELMANN, Wilson. As nanotecnologias e a propriedade intelectual: desafios e possibilidades à gestão transdisciplinar na inovação. In: BOFF, Salete Oro; PIMENTEL, Luis Otávio (Org.). A proteção jurídica da inovação tecnológica. 1. ed. Passo Fundo: Edimed, 2011a. V. 1.

. O direito das nanotecnologias e a (necessária) reconstrução dos elementos estruturantes da categoria do "direito subjetivo". In: STRECK, Lenio Luiz; ROCHA, Leonel Severo; ENGELMANN, Wilson (Org.). Constituição, sistemas sociais e hermenêutica: anuário do programa de Pós-Graduação em Direito da Unisinos: Mestrado e Doutorado: n. 11. Porto Alegre: Livraria do Advogado Editora; São Leopoldo: Unisinos, 2014. p. 339-359. Cap. XVI.

O direito frente aos desafios trazidos pelas nanotecnologias. In: STRECK, Lenio Luiz; ROCHA, Leonel Severo; ENGELMANN, Wilson (Org.). Constituição, sistemas sociais e hermenêutica: anuário do programa de Pós-Graduação em Direito da Unisinos: Mestrado e Doutorado: n. 10. Porto Alegre: Livraria do Advogado Editora; São Leopoldo: Unisinos, 2013. p. 301-312. Cap. XVI.

. Os avanços nanotecnológicos e a (necessária) revisão da Teoria do Fato Jurídico de Pontes de Miranda: compatibilizando "riscos" como o "direito à informação" por meio do alargamento da noção de "suporte fático". In: CALLEGARI, André Luís; STRECK, Lenio Luiz; ROCHA, Leonel Severo (Org.). Constituição, sistemas sociais e hermenêutica: anuário do programa de Pós-Graduação em Direito da Unisinos: Mestrado e Doutorado: n. 8. Porto Alegre: Livraria do Advogado Editora; São Leopoldo: Unisinos, 2011b. p. 339363. Cap. XV.

ESTADÃO. Estudo chinês documenta mortes por nanotecnologia. [S.1.], 19 ago. 2009. Disponível em: <http://ciencia.estadao.com.br/noticias/geral,estudo-chines-documenta-mortes-por-nanotecnologia,421451>. Acesso em: 11 set. 2016. 
FIORILLO, Celso Antônio Pacheco. Curso de direito ambiental brasileiro. 14. ed., rev. ampl. e atual. São Paulo: Saraiva, 2013.

GARCIA, Gustavo Filipe Barbosa. Curso de direito do trabalho. 6. ed. rev. atual. e ampl. Rio de Janeiro: Forense, 2012.

GEMignAnI, Daniel; GEMignAni, Teresa Aparecida Asta. Meio ambiente de trabalho: precaução e prevenção - princípios norteadores de um novo padrão normativo. Revista TST, Brasília, v. 78, n. 1, p. 258-280, jan./mar. 2012. Disponível em: <http://webcache.googleusercontent.com/ search?q=cache:6OS10o7seMIJ:www.tst.jus.br/documents/1295387/4235912/ Meio\%2BAmbiente\%2Bde\%2Btrabalho.\%2BPrecau\%25C3\%25A7\%25C3\%25A3o \%2Be\%2Bpreven\%25C3\%25A7\%25C3\%25A3o.\%2BPrinc\%25C3\%25ADpios\%2Bno rteadores\%2Bde\%2Bum\%2Bnovo\%2Bpadr\%25C3\%25A3o\%2Bnormativo\%3Fve rsion\%3D1.1+\&cd=2\&hl=pt-BR\&ct=clnk\&gl=br\&client=firefox-b-ab $>$. Acesso em: 11 set. 2016.

GÓES, Maurício de Carvalho; ENGELMANN, Wilson. Direito das nanotecnologias e o meio ambiente do trabalho. Porto Alegre: Livraria do Advogado, 2015. HOHENDORFF, Raquel Von; COIMBRA, Rodrigo; ENGELMANN, Wilson. As nanotecnologias, os riscos e as interfaces com o direito à saúde do trabalhador. In: Revista de Informação Legislativa, Brasília, ano 53, n. 209, p. 151-172, jan./ mar. 2016.

HOHENDORFF, Raquel Von; ENGELMANN, Wilson. Nanotecnologias aplicadas aos agroquímicos no Brasil: a gestão de riscos a partir do diálogo entre as fontes do direito. Curitiba: Juruá, 2014.

The Management of Risks by the Law in the Nano Agrochemicals Scenario. 1 ed. Saarbrücken: LAMERT Academic Publishing, 2015.

KIMBRELL, George A. Governance of nanotechnology and nanomaterials: principles, regulation and renegotiating the social contract. Journal of Law, Medicine and Ethics, a. 37, n. 706, winter 2009. Disponível em: <http://webcache.googleusercontent.com/search?q=cache:lpXWYM17rWQJ:www.icta. org/files/2012/05/100993_Nano_and_You_lo.pdf+\&cd=1\&hl=pt-BR\&ct=clnk\&gl=br>. Acesso em: 27 ago. 2016. 
MELO, Raimundo Simão de. Direito ambiental do trabalho e a saúde do trabalhador: responsabilidades, dano material, dano moral, dano estético, indenização pela perda de uma chance, prescrição. 3. ed. São Paulo: LTr, 2013.

NATIONAL INSTITUTE FOR OCCUPATIONAL SAFETY AND HEALTH (Niosh). Current strategies for engineering controls in nanomaterial production and downstream handling processes. Cincinnati, OH: U.S. Department of Health and Human Services, Centers for Disease Control and Prevention, National Institute for Occupational Safety and Health, DHHS (NIOSH). Publication n. 2014-102, 2013a. Disponível em: <https://webcache.googleusercontent.com/search?q=cache:KoRm3MPkbN0J:https:// www.cdc.gov/niosh/docs/2014-102/pdfs/2014-102.pdf $+\& c d=1 \&$ hl=pt-BR\&ct=clnk\&gl=br\&client=firefox-b>. Acesso em: 28 ago. 2016.

Protecting the nanotechnology workforce: NIOSH nanotechnology research and guidance strategic plan, 2013-2016. Cincinnati, OH: U.S. Department of Health and Human Services, Centers for Disease Control and Prevention, National Institute for Occupational Safety and Health, DHHS (NIOSH). Publication 2014-106, 2013b. Disponível em: <http://webcache.googleusercontent.com/search?q=cache:yjrp66vDOVMJ:www.cdc.gov/niosh/docs/2014106/pdfs/2014-106.pdf $+\& c d=1 \&$ hl=pt-BR\&ct=clnk\&gl=br\&client=firefox-b $>$. Acesso em: 28 ago. 2016.

NUNES, Paulo. Conceito de árvore de decisão. 2015. Disponível em: <http:// knoow.net/cienceconempr/gestao/arvore-de-decisao/htm>. Acesso em: 28 ago. 2016.

ORGANIZAÇÃO INTERNACIONAL DO TRABALHO (OIT). A prevenção das doenças profissionais. 1. ed. Lisboa: Bureau Internacional do Trabalho, abr. 2013. Disponível em: <http://www.oitbrasil.org.br/sites/default/files/topic/ gender/doc/safeday2013\%20final_1012.pdf>. Acesso em: 11 set. 2016.

. Convenção n. 155. 1981. Disponível em: <http://www.oitbrasil.org.br/ node/504>. Acesso em: 11 set. 2016. 
OSHIRO, Maria de Lourdes; HOHENDORFF, Raquel Von; ENGELMANN, Wilson. As nanotecnologias no meio ambiente do trabalho: a precaução para equacionar os riscos do trabalhador. In: Cadernos ibero-americanos de direito sanitário. CONGRESSO IBERO-AMERICANO DE DIREITO SANITÁRIO, 3., CONGRESSO BRASILEIRO DE DIREITO SANITÁRIO, 2., 2013. Anais... v. 2, n. 2, p. 668-683, jul./dez. 2013. Disponível em: <http://publicaciones.fmdv. org/ojs/index.php/cuadernosderechosanitario/article/view/74/103>. Acesso em: 11 set. 2016.

ROCHA, Julio César de Sá da. Direito ambiental do trabalho: mudanças de paradigma na tutela jurídica à saúde do trabalhador. São Paulo: Atlas, 2013.

SANCHEZ, Adilson. A contribuição social ambiental: direito ambiental do trabalho: SAT, NTEP, FAP, aposentadoria especial. São Paulo: Atlas, 2009.

SINDICATO DA INDÚSTRIA DE PRODUTOS FARMACÊUTICOS NO ESTADO DE SÃO PAULO (SINDUSFARMA); SINDICATO DOS TRABALHADORES NAS INDÚSTRIAS QUIIMICAS, FARMACÊUTICAS, PLÁSTICAS, DE EXPLOSIVOS, ABRASIVOS, FERTILIZANTES E LUBRIFICANTES DE OSASCO E COTIA. Termo aditivo à convenção coletiva de trabalho. São Paulo, 19 abr. 2012. Disponível em: <http://www.sindusfarma.org.br/informativos/ Aditivo_Osasco2012_2013.pdf $>$. Acesso em: 11 set. 2016.

SUPIOT, Alain. Crítica del derecho del trabajo. Traducción José Luis Gil y Gil. España: Ministerio de Trabajo y Asuntos Sociales, 1996.

. Homo juridicus: ensaio sobre a função antropológica do direito. Tradução Maria Ermantina de Almeida Prado Galvão. São Paulo: WMF Martins Fontes, 2007.

UNITED NATIONS EDUCATIONAL SCIENTIFIC AND CULTURAL ORGANIZATION (Unesco). Éthique et politique des nanotechnologies. 2007. Disponível em: <http://webcache.googleusercontent.com/search?q=cache:QKjNLFlmUYYJ:unesdoc.unesco.org/images/0014/001459/145951f.pdf $+\& c d=1 \&$ hl=pt-BR\&ct=clnk\&gl=br\&client=firefox-b>. Acesso em: 27 ago. 2016. 
WEYERMÜLLER, André Rafael; FLORES, André Stringhi; ENGELMANN, Wilson. Nanoteconologias, marcos regulatórios e direito ambiental. Curitiba: Honoris Causa, 2010.

ZUBEN, Fernando J. Von; ATTUX, Romis R. F. Árvores de decisão DCA/ FEEC/Unicamp. Disponível em: <http://webcache.googleusercontent.com/ search?q=cache:S46JMAfEJFsJ:ftp://ftp.dca.fee.unicamp.br/pub/docs/vonzuben/ia004_1s10/notas_de_aula/topico7_IA004_1s10.pdf+\&cd=1\&hl=pt-BR\&ct=clnk\&gl=br\&client=firefox-b-ab>. Acesso em 28 ago. 2016. [O conteúdo deste tópico está baseado no capítulo de Árvores de Decisão constante da tese de Doutorado de Márcio Porto Basgalupp (2010) e também em FERREIRA (2008)].

Recebido em: 26/6/2016

Revisões requeridas em: 16/8/2016

Aceito em: $12 / 9 / 2016$ 